\title{
Long Electron-Hole Diffusion Length in High- Quality Lead-Free Double Perovskite Films
}

Weihua Ning, Feng Wang, Bo Wu, J un Lu, Zhibo Yan, Xianjie Liu, Youtian Tao, J unMing Liu, Wei Huang, Mats Fahlman, Lars Hultman, Tze Chien Sum and Feng Gao

The self-archived postprint version of this journal article is available at Linköping University Institutional Repository (DiVA):

http:// urn.kb.se/ resolve?urn=urn:nbn:se:liu:diva- 148245

N.B.: When citing this work, cite the original publication.

Ning, W., Wang, F., Wu, Bo, Lu, J ., Yan, Z., Liu, X., Tao, Y., Liu, J., Huang, W., Fahlman, M., Hultman, L., Sum, T. C., Gao, F., (2018), Long Electron-Hole Diffusion Length in High-Quality Lead-Free Double Perovskite Films, Advanced Materials, 30(20), 1706246.

https:// doi.org/ 10.1002/ adma.201706246

Original publication available at:

https:// doi.org/ 10.1002/ adma.201706246

Copyright: Wiley (12 months)

http:// eu.wiley.com/ WileyCDA/ 
DOI: 10.1002/((please add manuscript number))

\section{Submitted to \\ ADNANCED
MAAERTALIS}

Article type: Communication

\section{Long Electron-Hole Diffusion Length in High-Quality Lead-Free Double Perovskite Films}

Weihua Ning, Feng Wang, Bo Wu, Jun Lu, Zhibo Yan, Xianjie Liu, Youtian Tao, Jun-Ming Liu, Wei Huang, Mats Fahlman, Lars Hultman, Tze Chien Sum,* and Feng Gao*

Dr. W. Ning, Dr. F. Wang, Dr. J. Lu, Dr. Z. Yan, Dr. X. Liu, Prof. M. Fahlman, Prof. L. Hultman, Prof. F. Gao

Department of Physics, Chemistry, and Biology (IFM), Linköping University, Linköping SE-581 83, Sweden

E-mail: fenga@ifm.liu.se

Dr. W. Ning, Prof. Y. Tao, Prof. W. Huang

Key Lab for Flexible Electronics \& Institute of Advanced Materials, Jiangsu National Synergistic Innovation Center for Advanced Materials (SICAM), Nanjing Tech University, 30 South Puzhu Road, Nanjing, 211816 PR China

Dr. B. Wu, Prof. T. C. Sum

Division of Physics and Applied Physics, School of Physical and Mathematical Sciences, Nanyang Technological University (NTU), 21 Nanyang Link, 637371 Singapore.

E-mail: tzechien@ntu.edu.sg

Dr. Z. Yan, Prof. J.-M. Liu

Laboratory of Solid State Microstructures and Innovation Center of Advanced Microstructures, Nanjing University, Nanjing 210093, China

Keywords: double perovskite, lead free, long diffusion length, planar solar cell

Solution-processed lead halide perovskites have shown superior optoelectronic properties, including strong and tunable light absorption/emission, long carrier diffusion lengths, and high carrier mobilities. ${ }^{[1,2]}$ As a result, the power conversion efficiencies of perovskite solar cells have increased from $3.8 \%$ to $22.1 \%$ within only a few years, making perovskites the fastestadvancing technology in the photovoltaic history. ${ }^{[3,4]}$ To ensure the sustainability of the perovskite photovoltaic technology, the number of studies to address the lead $(\mathrm{Pb})$ toxicity and device stability issues has increased. ${ }^{[5-7]}$ The most obvious option for lead-free perovskites is the substitution of $\mathrm{Pb}^{2+}$ with another divalent cation (e.g., germanium $\left(\mathrm{Ge}^{2+}\right)$ or tin $\left.\left(\mathrm{Sn}^{2+}\right)\right) .{ }^{[8,9]}$ 


\section{Submitted to}

\section{ADVANCED}

Unfortunately, the resulting perovskites based on $\mathrm{Sn}^{2+}$ or $\mathrm{Ge}^{2+}$ are easily oxidized by $\mathrm{O}_{2}$, limiting their practical applications. ${ }^{[10]}$ Bismuth (Bi)-based organic-inorganic metal halides have also been studied as an alternative for solar cell applications. ${ }^{[11]}$ Different from the 3-D lead-based perovskites, the 0-D to 2-D structures of Bi-based organic-inorganic halides lead to strongly bound excitons with low mobilities. ${ }^{[5]}$

A new generation of perovskites, lead-free halide double perovskites with a general formula of $\mathrm{A}_{2} \mathrm{M}^{+} \mathrm{M}^{3+} \mathrm{X}_{6}$, where both $\mathrm{A}^{+}$and $\mathrm{M}^{+}$are mono-valent cations, $\mathrm{M}^{3+}$ is a trivalent cation, and $\mathrm{X}$ is a halide, provide rich substitutional chemistry and promising optoelectronic properties. ${ }^{[12]}$ Several groups have successfully synthesized double perovskite powders and single crystals, and carried out crystal characterizations and fundamental studies. ${ }^{[13-15]}$ Double perovskites show tunable bandgaps spanning the visible to near-infrared spectra and possess relatively low carrier effective masses that are favorable for efficient charge transport and extraction, similar to 3-D lead-based perovskites. ${ }^{[14,16]}$ Moreover, these materials provide rich substitutional chemistry, which can dramatically change their photophysical properties. ${ }^{[17,18]}$ For example, Tldoped $\mathrm{Cs}_{2}\left(\mathrm{Ag}_{1-\mathrm{a}} \mathrm{Bi}_{1-\mathrm{b}}\right) \mathrm{Tl}_{\mathrm{x}} \mathrm{Br}_{6}(\mathrm{x}=0.075)$ results in a decrease in the bandgap of ca. $0.5 \mathrm{eV} .^{[18]}$ Recent first-principle calculations also indicate that halide double perovskites are promising candidates for photovoltaic applications. ${ }^{[16,19,20]}$ Furthermore, these double perovskites are much more stable than $\mathrm{Ge}$ or $\mathrm{Sn}$ perovskites in repelling the attacks by $\mathrm{O}_{2}$ and $\mathrm{H}_{2} \mathrm{O} .^{[15,21]}$ However, since the precursors of double perovskites cannot dissolve in common solvents (for example, Dimethylformamide-DMF) which are frequently for lead-based perovskites, it is still a challenge to fabricate double perovskite solar cells. ${ }^{[22]}$ And also, most of the fundamental questions concerning the photophysics of double perovskite films remain unexplored and unknown due in part to the lack of uniform and high-quality films.

In this work, we demonstrate the first double perovskite solar cells using the planar structure. We prepare high-quality films with single-layer $\mathrm{Cs}_{2} \mathrm{AgBiBr}_{6}$ crystals. Through photo-physical investigations, we find the coexistence of excitons and free carriers in the material. These 
$\mathrm{Cs}_{2} \mathrm{AgBiBr}_{6}$ films show a long photoexcited carrier diffusion length of approximately $110 \mathrm{~nm}$.

The resulting solar cells based on planar $\mathrm{TiO}_{2}$ exhibit an average power conversion efficiency (PCE) over 1\%.

The high quality $\mathrm{Cs}_{2} \mathrm{AgBiBr}_{6}$ films are prepared through a one-step spin-coating process from single-crystal $\mathrm{Cs}_{2} \mathrm{AgBiBr}_{6}$ solutions. Figure $1 \mathrm{a}$ and $1 \mathrm{~b}$ show typical scanning electron microscopy (SEM) images of the perovskite films from a $0.5 \mathrm{M}$ solution. The surface roughness $(\mathrm{Rq})$ is only approximately $24 \mathrm{~nm}$ (Figure S1). The smooth film is essential for the following photoluminescence (PL)-quenching measurements and photovoltaic performance. The films are composed of closely packed polycrystalline grains with diameters of 100-500 nm. To examine each individuate grains, TEM and selected electron diffraction (SAED) are performed. Impressively, both TEM and SAED reveal that each grain is a single crystal (Figure 1c), although the films are polycrystalline. This feature is beneficial for the photovoltaic performance since there is no grain boundary in between from top to bottom of the film. The limited grain boundary in the vertical direction would be important for efficient carrier transfer in devices. In addition, the XRD pattern confirms the pure phase in the $\mathrm{Cs}_{2} \mathrm{AgBiBr} 6$ films, matching well with the results of the simulation (Figure 1d).

Figure 2 shows the UV-Vis absorption of $\mathrm{Cs}_{2} \mathrm{AgBiBr}_{6}$ thin film. There are three parts in the absorption spectrum: below $400 \mathrm{~nm}$, with a flat absorption feature; an excitonic absorption band in the region from $400-500 \mathrm{~nm}$; and a very weak indirect absorption band between $500-538 \mathrm{~nm}$, similar to that in single crystals. ${ }^{[14]}$ The absorption coefficients at $439 \mathrm{~nm}$ reach up to $1 \times 10^{5} \mathrm{~cm}^{-}$ 1. By using the Elliott formula, the direct bandgap $\left(E_{g d}\right)$ is approximately $3.26 \mathrm{eV}$ (See Supporting Information and Figure S2). The indirect band gap cannot be determined by the thin films due to its weak absorption, but was extracted previously to be approximately $1.95 \mathrm{eV}$ from single crystals. ${ }^{[14]}$

We obtain PL spectra and time-resolved photoluminescence (TRPL) studies to understand the photoexcited species. As shown in Figure 2a, the broad PL peak centered at approximately 


\section{Submitted to

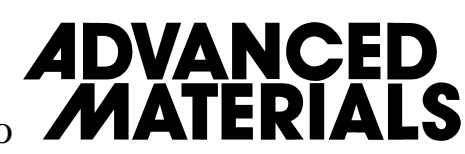

$2.0 \mathrm{eV}(620 \mathrm{~nm})$ can be attributed to the indirect bandgap emission, as it corresponds well with the indirect absorption and emission found previously in single crystals. ${ }^{[14]}$ The excitation intensity dependence of PL intensity just after photo-excitation is generally a good indicator of the nature of the radiative recombination processes. ${ }^{[23]}$ Briefly, the initial PL intensity exhibits a quadratic dependence on the photo-excitation density for emission by free-carrier band edge recombination: $\left.\mathrm{PL}\right|_{\mathrm{t}=0} \propto n^{2}$, where $n$ is the photo-excitation density (See Supporting Information for detailed explanation). For emission by radiative recombination of excitons or free carriers with doped carriers, $\left.\mathrm{PL}\right|_{\mathrm{t}=0} \propto n$. ${ }^{[24,25]}$ It is noted that the PL signal is too weak to be detected if the carrier density below $10^{16} \mathrm{~cm}^{-3}$. When the carrier density is between $10^{16}$ and $10^{17} \mathrm{~cm}^{-3}$, the PL intensity shows power-dependence on the carrier density with a scaling factor $(\lambda)$ of 1.34 (Figure 2b). This value suggests either the coexistence of radiative recombination of the free electrons-holes (recombination order 2) and the free carriers with doped carriers (recombination order 1), or the coexistence of excitons (recombination order 1) and free electrons-holes in the measured excitation density range. However the doped carrier density measured by Hall Effect is on the order of $10^{13} \mathrm{~cm}^{-3}$, which is not comparable to the photo-excitation density. Hence, it would be more reasonable to conclude that excitons and free carriers coexist in the double perovskite films, and the exciton possesses a higher ratio in the measured excitation range. Further increasing the carrier density to above $10^{17} \mathrm{~cm}^{-3}$ causes the linear scale factor $(\lambda)$ to decrease to 0.85 . Meanwhile, the effective PL lifetime ( $\tau_{\text {eff }}$, the time the PL intensity drops to 1/e of its maximum value) also decreases continuously with increasing carrier densities (Figure S3), implying strong high-order recombination such as exciton-carrier and exciton-exciton Auger recombination at high carrier densities. This unusual photophysical behavior contrasts from that of lead-based perovskites and further investigations are warranted.

To quantify the carrier diffusion length of the $\mathrm{Cs}_{2} \mathrm{AgBiBr}_{6}$ film, we carry out transient photoluminescence (TRPL) experiments. The thicknesses of perovskite films are 


\section{Submitted to

approximately $100 \mathrm{~nm}$, and the quenching samples are prepared by spin-coating layers of either a hole-transporting acceptor (Spiro-MeOTAD) or an electron-accepting fullerene (PC $\left.{ }_{61} \mathrm{BM}\right)$ on top of the perovskite film. The results show that the PL decay dynamics of $\mathrm{Cs}_{2} \mathrm{AgBiBr}_{6}$ film can be fitted by a bi-exponential decay function at low excitation density, with time constants being $\tau_{1}=2.5 \pm 0.4 \mathrm{~ns}$ (52\%), $\tau_{2}=35 \pm 1 \mathrm{~ns}$ (48\%), which arises from the crystal size inhomogeneity. As a result, the effective excitation lifetime $\tau_{\text {eff }}$ (the time for the PL decaying to 1/e of its initial intensity: $\sum_{i} A_{i} \exp \left(-\frac{t}{\tau_{\text {eff }}}\right)=\sum_{i} A_{i} \exp \left(-\frac{t}{\tau_{i}}\right)$, where $\tau_{i}$ is the $i_{\text {th }}$ fitted lifetime component of the decay curve and $A_{i}$ is its weighted amplitude) in pristine film is $13.7 \pm 0.4 \mathrm{~ns}$ (Figure 2c). After the film is coated with $\mathrm{PC}_{61} \mathrm{BM}$, the PL decays much faster, with $\tau_{\text {eff }}$ being $2.4 \pm 0.4$ ns. This indicates highly efficient electron transfer from the perovskite to $\mathrm{PC}_{61} \mathrm{BM}$. A similar value of $2.6 \pm 0.2$ ns was obtained for Spiro-MeOTAD coated perovskite films. Based on the PL quenching model, ${ }^{[25]}$ we estimate an average photoexcitation mobility of $0.37 \pm 0.15$ $\mathrm{cm}^{2} \mathrm{~V}^{-1} \mathrm{~s}^{-1}$, and the photoexcitation diffusion length for electrons and holes approximately 110 $\pm 20 \mathrm{~nm}$. The similarity of diffusion length is consistent with the dominance of excitons as the primary photoexcitation species in the excitation density range. With photoexcitation diffusion lengths above $100 \mathrm{~nm}$, the double perovskite polycrystalline film already shows excellent carrier diffusion properties comparable to those of lead-based perovskite films possessing typical carrier diffusion lengths of $100 \mathrm{~nm}-1 \mu \mathrm{m} .{ }^{[25,26]}$ It is noted that the diffusion length measurements were performed at a carrier density of $\sim 5 \times 10^{16} \mathrm{~cm}^{-3}$, which is expected to be higher than that of devices under solar illumination $\left(10^{15}-10^{16} \mathrm{~cm}^{-3}\right) \cdot{ }^{[27]}$ It is difficult to make sure whether there is a trap-filling effect during the TRPL measurements, as we did not observe an increase of carrier lifetime with increasing the carrier density (Figure S4), possibly due to low trap density in the devices. Therefore, trap-filling as well as the tendency of the photo- 


\section{Submitted to

excitation species changing from excitons to free carriers were not considered in the measurements.

The long diffusion lengths and high mobility of the $\mathrm{Cs}_{2} \mathrm{AgBiBr}_{6}$ films implies that carriers can travel through the film; thus solar cells are expected to operate well on planar-structured devices. The detailed information about the fabrication of an ITO/compact $\mathrm{TiO}_{2} / \mathrm{Cs}_{2} \mathrm{AgBiBr}_{6} /$ spiro-MeOTAD/Au device is described in the Supporting Information. The thickness-dependent photocurrent is compared by varying the concentration of the solution as follows: $0.4 \mathrm{M}, 0.45 \mathrm{M}, 0.5 \mathrm{M}$, and $0.55 \mathrm{M}$. The corresponding thicknesses are $145 \pm 12 \mathrm{~nm}$, $170 \pm 15 \mathrm{~nm}, 205 \pm 10 \mathrm{~nm}$, and $223 \pm 10 \mathrm{~nm}$, respectively. $J$ - $V$ results show that the photocurrent initially increases with increasing thickness, with an optimised $J_{s c} \sim 1.7 \mathrm{~mA} / \mathrm{cm}^{2}$ at a $\sim 205 \mathrm{~nm}$ thickness (Figure 2d and Figures S5 and S6). Further increasing the thickness to 223 nm decreases the photocurrent to $\sim 1.1 \mathrm{~mA} / \mathrm{cm}^{2}$. The optimum thickness of $\sim 205 \mathrm{~nm}$ confirms the long diffusion length of $\mathrm{Cs}_{2} \mathrm{AgBiBr}_{6}$ films.

The annealing temperature also has a significant effect on the device performance. The $V_{\text {oc }}$ values are all approximately $1.0 \mathrm{~V}$ for different annealing temperatures (Figure S7). However, $J_{s c}$ and FF values firstly gradually increase with increasing annealing temperatures, and then drop down when the temperature is above $250{ }^{\circ} \mathrm{C}$. This result can be rationalised by considering the characteristics of crystallinity, grain size and pinholes of films together (Figure S8 and S9). The grain size and crystallinity gradually increase with increasing annealing temperature. Unfortunately, a large number of pinholes appear when the annealing temperature increases above $300{ }^{\circ} \mathrm{C}$. Further increasing the annealing temperature to $400^{\circ} \mathrm{C}$ results in the degradation of the films (Figure S8).

The optimized devices exhibit an average PCE of 1.05\% (averaged from 40 devices from 5 different batches) and outstanding PCE of $1.22 \%$ with a $V_{\text {oc }}$ of $1.06 \mathrm{~V}$ (Figure 3c). Figure 3d shows the corresponding stabilized power output with a bias of $0.82 \mathrm{~V}$. The device exhibits a rapid response after illumination, resulting in a stable PCE of $1.17 \%$ over $600 \mathrm{~s}$ of illumination. 


\section{Submitted to \\ ADVANCED}

Notably, there is almost no hysteresis behaviour in the $J$ - $V$ curves, implying less trapping/detrapping or ion migration in $\mathrm{Cs}_{2} \mathrm{AgBiBr}_{6}$ compared with lead-based hybrid perovskites. Very recently, Scanlon and co-workers estimated the spectroscopic limited maximum efficiency (SLME) of $\mathrm{Cs}_{2} \mathrm{AgBiBr}_{6}(200 \mathrm{~nm})$ to be $7.92 \% .{ }^{[28]}$ The SLME takes into account the strength of optical absorption and the nature of the band gap in the overall theoretical efficiency of an absorber material. ${ }^{[29]}$ As an indirect band gap semiconductor, the SLME of $\mathrm{Cs}_{2} \mathrm{AgBiBr}_{6}$ is significantly dependent on the thickness of the films, and hence future approaches are required either to enhance the thickness of $\mathrm{Cs}_{2} \mathrm{AgBiBr}_{6}$ films or to make $\mathrm{Cs}_{2} \mathrm{AgBiBr}_{6}$ into direct bandgap semiconductor, e.g., through doping. ${ }^{[18]}$

We note that the efficiency we obtained (up to 1.22\%) is much lower than the SLME of $\mathrm{Cs}_{2} \mathrm{AgBiBr}_{6}$ at $200 \mathrm{~nm}$, in spite of high crystal quality. One of the reasons might be due to the fact that the charge extraction efficiency of $\mathrm{TiO}_{2}$ for the $\mathrm{Cs}_{2} \mathrm{AgBiBr}_{6}$ films is not as efficient as those of Spiro-MeOTAD and $\mathrm{PC}_{61} \mathrm{BM}$. PL intensity and decay of $\mathrm{TiO}_{2} / \mathrm{Cs}_{2} \mathrm{AgBiBr}_{6}$ show no obvious difference compared with those of pure $\mathrm{Cs}_{2} \mathrm{AgBiBr}_{6}$ (Figure S10). Since the band energy of $\mathrm{Cs}_{2} \mathrm{AgBiBr}_{6}$ matches with those of $\mathrm{TiO}_{2}$ and Spiro-OMeTAD (Figure S11), the reason is possibly due to the presence of an interfacial barrier from surface defects, similar to the $\mathrm{MAPbI}_{3}: \mathrm{TiO}_{2}$ heterojunction. ${ }^{[30]}$ We also estimate the theoretical $J_{S C}$ value for $\mathrm{Cs}_{2} \mathrm{AgBiBr}_{6}$ devices based on the diffusion length values and the absorption coefficient. ${ }^{[31]}$ The calculated theoretical $J_{s c}$ value for $\mathrm{Cs}_{2} \mathrm{AgBiBr}_{6}$ devices can be around $5.2 \mathrm{~mA} / \mathrm{cm}^{2}$, which is higher than $1.7 \mathrm{~mA} / \mathrm{cm}^{2}$ in our results. This also implies poor charge extraction of $\mathrm{TiO}_{2}$ in the devices. We thus further fabricate an ITO/perovskite/Spiro-MeOTAD/Au device without $\mathrm{TiO}_{2}$ to understand the charge extraction process. The resulting $J_{\mathrm{sc}}$ is approximately $1.7 \mathrm{~mA} / \mathrm{cm}^{2}$ (Figure S12), which is almost the same as that of devices with $\mathrm{TiO}_{2}$. This result confirms less effective electron extraction by $\mathrm{TiO}_{2}$. However, the $V_{\text {oc }}$ of the devices without $\mathrm{TiO}_{2}$ is only approximately $0.5 \mathrm{~V}$, much lower than the ca. $1.0 \mathrm{~V}$ shown with $\mathrm{TiO}_{2}$. The high $V_{\text {oc }}$ suggests that $\mathrm{TiO}_{2}$ can prevent the carrier recombination at the ITO side. 


\section{Submitted to

In summary, we fabricate a uniform $\mathrm{Cs}_{2} \mathrm{AgBiBr}_{6}$ thin solid film of high crystal quality through a one-step spin-coating process from single-crystal $\mathrm{Cs}_{2} \mathrm{AgBiBr}_{6}$ solution. Upon excitation, excitons and free carriers co-exist in double perovskite films, with a long diffusion length of approximately $110 \mathrm{~nm}$. We achieve an average PCE over 1\% based on a planar device structure with a maximum value of $1.22 \%$. The photovoltaic performance is expected to be further boosted by replacing the $\mathrm{TiO}_{2}$ (used presently in this study) with more suitable ETL materials and by increasing the film thickness while maintaining the film quality. In addition, it will be favourable to develop direct bandgap double perovskites, e.g. through doping. The long carrier diffusion length of high-quality double perovskite films open a route towards developing environmentally-friendly perovskite-based solar cells. 


\section{Experimental Section:}

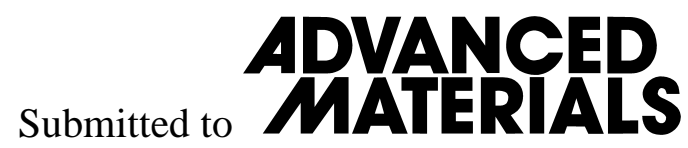

$\mathrm{Cs}_{2} \mathrm{AgBiBr}_{6}$ Single Crystals Synthesis: $\mathrm{CsBr}$ (213 mg, $\left.1.00 \mathrm{mmol}\right), \mathrm{BiBr}_{3}$ (225 mg, $0.5 \mathrm{mmol}$ ), and $\mathrm{AgBr}$ (94 mg, $0.5 \mathrm{mmol}$ ) were dissolved in $3 \mathrm{~mL}$ of $47 \% \mathrm{HBr}$. The solution was transferred to a Teflon-lined reactor. After reacting at $120^{\circ} \mathrm{C}$ for $24 \mathrm{~h}$, and cooling to room temperature slowly, red $\mathrm{Cs}_{2} \mathrm{AgBiBr}_{6}$ octahedral single crystals with the size of 2-5 mm can be collected (Figure S13). The yield is ca. 85\% calculated from Ag.

$\mathrm{Cs}_{2} \mathrm{AgBiBr}_{6}$ Solar Cell Fabrication: The $\mathrm{TiO}_{2}$ compact film precursor solution in ethanol consists of 0.3 M titanium isopropoxide (Sigma-Aldrich, 99.999\%) and 0.01 M HCl. An 35 nm dense $\mathrm{TiO}_{2}$ film was coated onto an ITO substrate by spinning a titanium precursor at 5000 rpm, followed by annealing at $200{ }^{\circ} \mathrm{C}$ for $2 \mathrm{~h}$. The synthesized $\mathrm{Cs}_{2} \mathrm{AgBiBr}_{6}$ single crystals were dissolved in DMSO with a temperature of $100{ }^{\circ} \mathrm{C}-130{ }^{\circ} \mathrm{C}$. After the crystals were completely dissolved, the solution was cooled to room temperature, and then deposited onto the $\mathrm{TiO}_{2} / \mathrm{ITO}$ substrate by spin-coating at $3000 \mathrm{rpm}$ for $60 \mathrm{~s}$. The films were annealed at $250{ }^{\circ} \mathrm{C}$ for $5 \mathrm{~min}$ in order to obtain better crystallization. The thickness of the $\mathrm{Cs}_{2} \mathrm{AgBiBr}_{6}$ films was controlled by varying the concentration of the precursor solution from $0.4 \mathrm{M}-0.55 \mathrm{M}$. The highest PCE value of $\mathrm{Cs}_{2} \mathrm{AgBiBr}_{6}$ solar cells was achieved from the $0.5 \mathrm{M}$ solution. The spiro-MeOTAD based hole-transfer layer was prepared by dissolving $60 \mathrm{mg}$ spiro-MeOTAD, $17.5 \mu \mathrm{L}$ lithiumbis(trifluoromethanesulfonyl)imide (Li-TFSI) solution (520 mg Li-TFSI in $1 \mathrm{~mL}$ acetonitrile), and $28.8 \mu \mathrm{L}$ 4-tert-butylpyridine in $1 \mathrm{~mL}$ chlorobenzene. The devices were put into a dry cabinet for $15 \mathrm{~h}$ for the oxidization of Spiro-MeOTAD. The hole-transfer layer was deposited by spincoating at 5000 rpm for 30 s. Finally, a 100-nm gold layer was deposited by thermal evaporation at a pressure of $1 \times 10^{-4}$ mbar. All device fabrication steps were carried out in a $\mathrm{N}_{2}$-purged glovebox.

Measurement and Characterization: The XRD patterns of the products were recorded with a X'Pert PRO X-ray diffractometer using Cu K $\alpha 1$ irradiation $(\lambda=1.5406 \AA$ ). The Ultravioletvisible absorption spectra were measured on a Shimadzu spectrophotometer (UV-2450). The 
Submitted to

general morphologies of the films were characterized by scanning electron microscopy (SEM, LEO 1550). The Atomic force microscope measurement was carried out using a Dimension 3100/NanoScope IV system equipped with a C-AFM module (Veeco, Bruker). Transmission electron microscopy (TEM) was performed in the FEI Tecnai G2 TF20 UT with a field emission gun operated at $200 \mathrm{kV}$ and a point resolution of $0.19 \mathrm{~nm}$. Sample thicknesses were measured using an Alpha step 500 Surface profilometer. The current density-voltage $(J-V)$ curves were measured (Keithley Instruments, 2400 Series SourceMeter) under simulated AM 1.5 Solar Simulator. The effective area of the cell was defined as $0.075 \mathrm{~cm}^{2}$. The EQE data were obtained using a solar cell spectral response measurement system (QE-R3011, Enli Technology Co. Ltd), and the light intensity at each wavelength was calibrated with a standard single-crystal Si photovoltaic cell. PL and TRPL measurements were performed using $400 \mathrm{~nm}$ femtosecond excitation pulses (> $50 \mathrm{fs}$ ). The laser pulses were generated by passing the strong $800 \mathrm{~nm}$ femtosecond laser beam (Coherent Libra, 50 fs) through a BBO crystal (frequency doubler). The emitted light was collected at a backscattering angle by a spectrometer (Acton, Spectra Pro 2500i) and CCD (Princeton Instruments, Pixis 400B) in PL measurements and by an Optronis Optoscope streak camera system which has an ultimate temporal resolution of 6 ps in TRPL measurements.

\section{Supporting Information}

Supporting Information is available from the Wiley Online Library or from the author. 


\section{Acknowledgements}

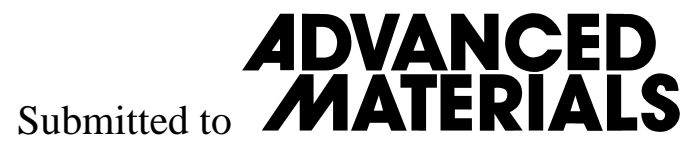

W. Ning and F. Wang contributed equally to this work. We thank Lijun Zhang (Jilin University, China) for insightful discussions. The work was financially supported by the Joint NTU-LiU PhD programme on Materials- and Nanoscience, the Swedish Government Strategic Research Area in Materials Science on Functional Materials at Linköping University (Faculty Grant SFO Mat LiU No 200900971), the European Commission Marie Skłodowska-Curie actions (NO. 691210); the European Commission SOLAR-ERA.NET, the Swedish Energy Agency (Energimyndigheten), and the Swedish Research Council (FORMAS); F.G. is a Wallenberg Academy Fellow; Both F.W. and Z.Y. are VINNMER Marie Skłodowska-Curie Fellows; W.N. is supported by the China Scholarship Council; T.C.S. acknowledges the financial support from the Ministry of Education Academic Research Fund Tier 1 grants RG101/15 and RG173/16, and Tier 2 grants MOE2014-T2-1-044, MOE2015-T2-2-015 and MOE2016-T2-1-034; and from the Singapore National Research Foundation through the Competitive Research Program NRF-CRP14-2014. L.H. acknowledges support from the Knut and Alice Wallenberg (KAW) Foundation for a Scholar Grant 2016.0358, and for support to the Linköping Ultra Electron Microscopy Laboratory.

Received: ((will be filled in by the editorial staff))

Revised: ((will be filled in by the editorial staff)) Published online: ((will be filled in by the editorial staff)) 


\section{References}

Submitted to

\section{ADNANCES
MAAERTALIS}

[1] M. A. Green, A. Ho-Baillie, H. J. Snaith, Nat. Photonics 2014, 8, 506.

[2] M. Gratzel, Nat. Mater. 2014, 13, 838.

[3] A. Kojima, K. Teshima, Y. Shirai, T. Miyasaka, J. Am. Chem. Soc. 2009, 131, 6050.

[4] W. S. Yang, B. W. Park, E. H. Jung, N. J. Jeon, Y. C. Kim, D. U. Lee, S. S. Shin, J. Seo, E. K. Kim, J. H. Noh, S. I Seok, Science 2017, 356, 1376.

[5] M. Lyu, J.-H. Yun, P. Chen, M. Hao, L. Wang, Adv. Energy Mater. 2017, DOI:10.1002/aenm.201602512.

[6] T. Leijtens, G. E. Eperon, N. K. Noel, S. N. Habisreutinger, A. Petrozza, H. J. Snaith, Adv. Energy Mater. 2015, 5, 1500963.

[7] F. Wang, W. Geng, Y. Zhou, H. H. Fang, C. J. Tong, M. A. Loi, L. M. Liu, N. Zhao, Adv. Mater. 2016, 28, 9986.

[8] F. Hao, C. C. Stoumpos, D. H. Cao, R. P. H. Chang, and M. G. Kanatzidis, Nat Photon 2014, 8, 489.

[9] C. C. Stoumpos, L. Frazer, D. J. Clark, Y. S. Kim, S. H. Rhim, A. J. Freeman, J. B. Ketterson, J. I. Jang, M. G. Kanatzidis. J. Am. Chem. Soc. 2015, 137, 6804.

[10] F. Wang, J. Ma, F. Xie, L. Li, J. Chen, J. Fan, N. Zhao, Adv. Funct. Mater. 2016, 26, 3417.

[11] B.-W. Park, B. Philippe, X. Zhang, H. Rensmo, G. Boschloo, E. M. J. Johansson, Adv. Mater. 2015, 27, 6806.

[12] I. N. Flerov, M. V. Gorev, K. S. Aleksandrov, A. Tressaud, J. Grannec, M. Couzi, Mater. Sci. Eng. R Rep. 1998, 24, 81.

[13] G. Volonakis, A. A. Haghighirad, R. L. Milot, W. H. Sio, M. R. Filip, B. Wenger, M. B. Johnston, L. M. Herz, H. J. Snaith, F. Giustino. J. Phys. Chem. Lett. 2017, 8, 772.

[14] A. H. Slavney, T. Hu, A. M. Lindenberg, H. I. Karunadasa, J. Am. Chem. Soc. 2016, 138, 2138. 
Submitted to

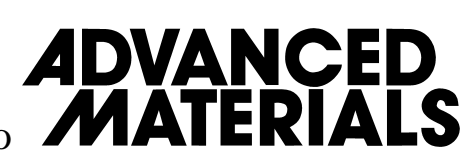

[15] E. T. McClure, M. R. Ball, W. Windl, P. M. Woodward, Chem. Mater. 2016, 28, 1348.

[16] G. Volonakis, M. R. Filip, A. A. Haghighirad, N. Sakai, B. Wenger, H. J. Snaith, F. Giustino. J. Phys. Chem. Lett. 2016, 7, 1254.

[17] K. Du, W. Meng, X. Wang, Y. Yan, D. B. Mitzi, Angew. Chem. Int. Ed. 2017, 56, 8158.

[18] A. H. Slavney, L. Leppert, D. Bartesaghi, A. Gold-Parker, M. F. Toney, T. J. Savenije, J. B. Neaton, H. I. Karunadasa, J. Am. Chem. Soc. 2017, 139, 5015.

[19] C. N. Savory, A. Walsh, D. O. Scanlon, ACS Energy Lett. 2016, 1, 949.

[20] X. G. Zhao, J. H. Yang, Y. Fu, D. Yang, Q. Xu, L. Yu, S. H. Wei, L. Zhang, J. Am. Chem. Soc. 2017, 139, 2630.

[21] F. Wei, Z. Deng, S. Sun, F. Zhang, D. M. Evans, G. Kieslich, S. Tominaka, Chem. Mater. 2017, 29, 1089.

[22] E. Greul, M. L. Petrus, A. Binek, P. Docampo, T. Bein, J. Mater. Chem. A 2017, DOI:10.1039/C7TA06816F

[23] T. Schmidt, G. Daniel, K. Lischka, J. Cryst. Growth 1992, 117, 748.

[24] B. Wu, Y. Zhou, G. Xing, Q. Xu, H. F. Garces, A. Solanki, T. W. Goh, N. P. Padture, T. C. Sum, Adv. Funct. Mater. 2017, 27, 1604818.

[25] Y. Yamada, T. Nakamura, M. Endo, A. Wakamiya, Y. Kanemitsu, J. Am. Chem. Soc. 2014, 136, 11610.

[25] G. Xing, N. Mathews, S. Sun, S. S. Lim, Y. M. Lam, M. Grätzel, S. Mhaisalkar, T. C. Sum, Science 2013, 342, 344.

[26] S. D. Stranks, G. E. Eperon, G. Grancini, C. Menelaou, M. J. Alcocer, T. Leijtens, L. M. Herz, A. Petrozza, H. J. Snaith, Science 2013, 342, 341.

[27] L. M. Herz, Annu. Rev. Phys. Chem. 2016, 67, 65. 


\section{Submitted to \\ ADVANCED}

[28] C. N. Savory, A. Walsh, D. O. Scanlon, ACS Energy Lett. 2016, 1, 949.

[29] L.P. Yu, A. Zunger, Phys. Rev. Lett. 2012, 108, 068071.

[30] G. Xing, B. Wu, S. Chen, J. Chua, N. Yantara, S. Mhaisalker, N. Mathews, T. C. Sum, Small 2015, 11, 3606.

[31] M. Ferri, D. Pinna, M. Grassi, Presented at 2010 IEEE, Kona, HI, USA, 1-4 Nov. 
 \\ Submitted to MATERIALS}
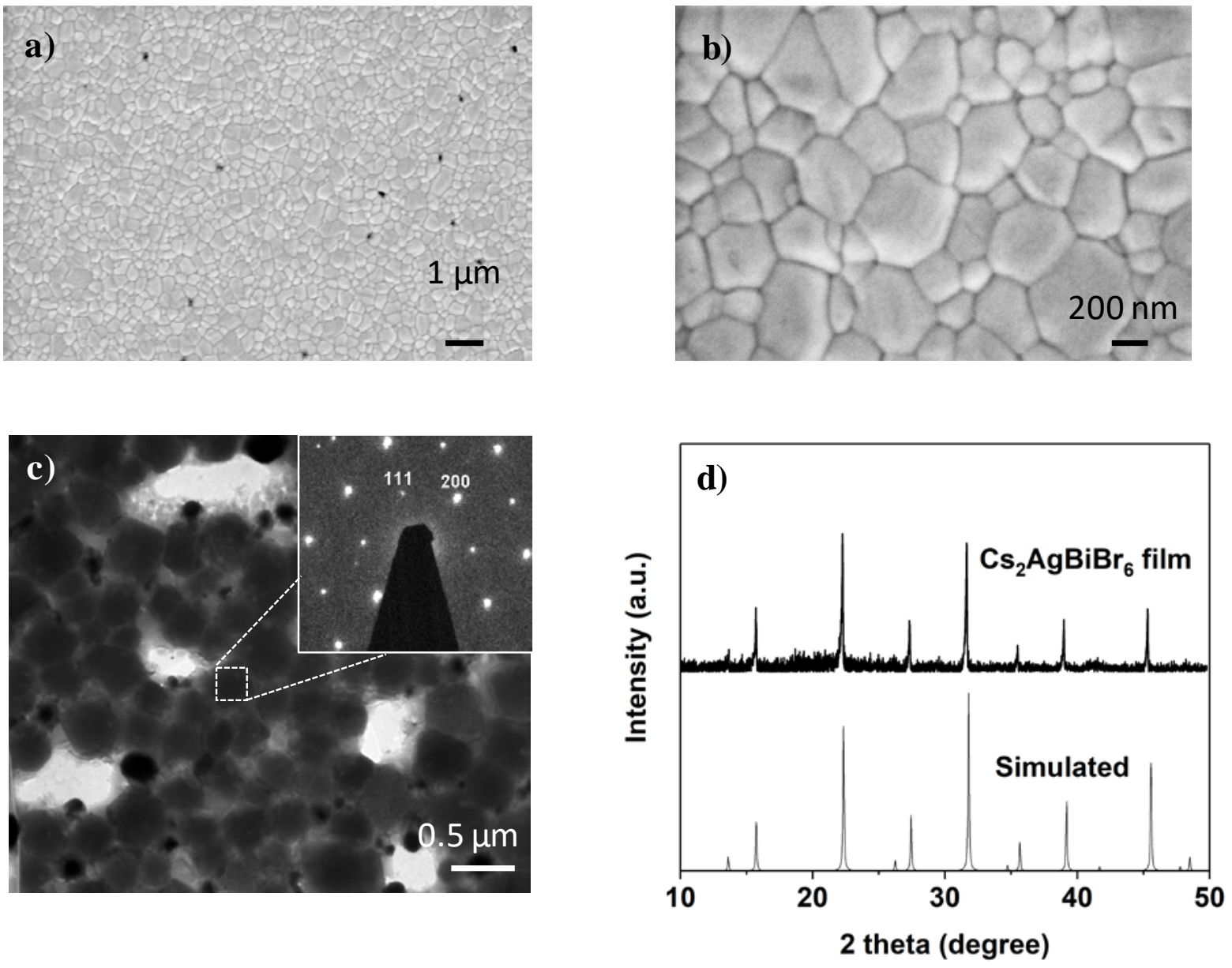

Figure 1. (a) Low-magnification and (b) high-magnification SEM images, (c) the TEM image and SAED pattern, and (d) the XRD pattern of the prepared $\mathrm{Cs}_{2} \mathrm{AgBiBr}_{6}$ films annealed at 250 ${ }^{\circ} \mathrm{C}$ for 5 min. 


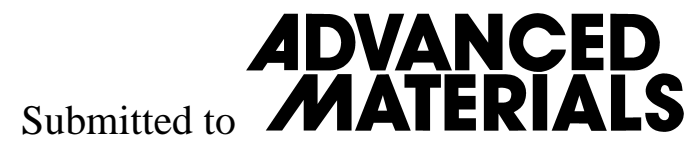

a)

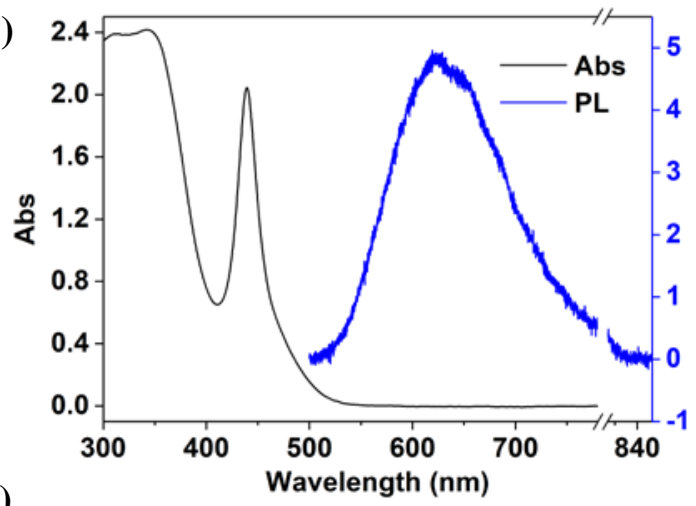

c)

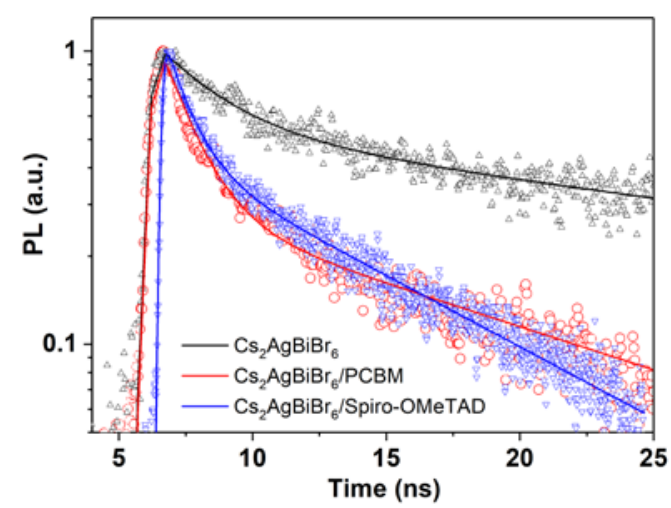

b)

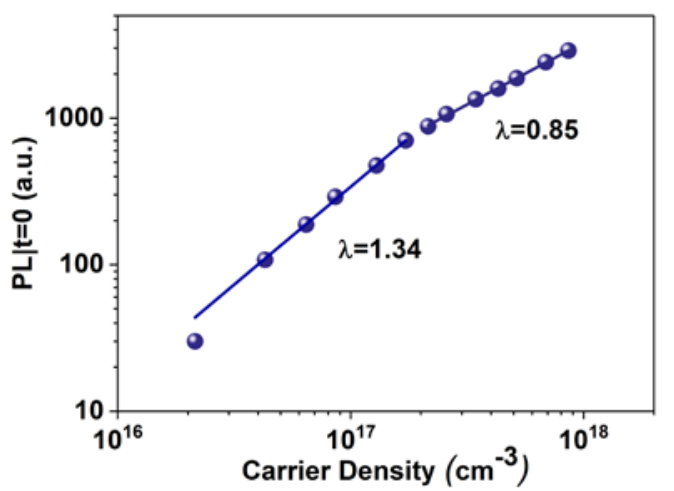

d)

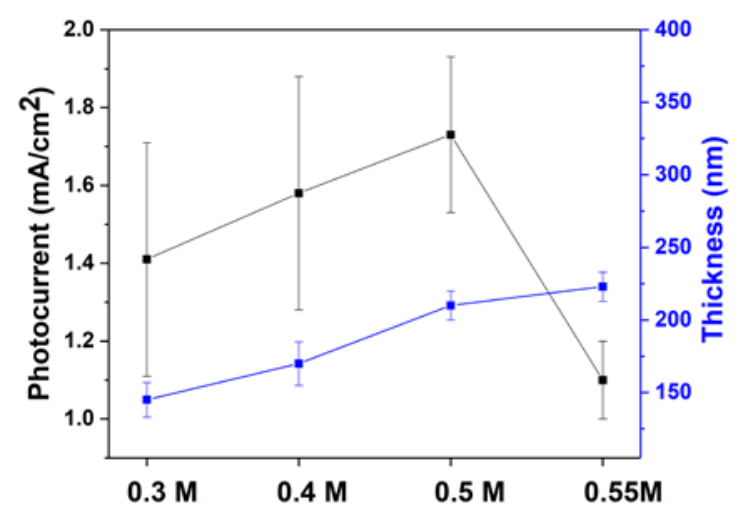

Figure 2. (a) UV-Vis absorption and PL spectra of a $100 \mathrm{~nm} \mathrm{Cs} 2 \mathrm{AgBiBr}_{6}$ film. (b) PL intensity as a function of carrier density, the PL intensities were the values just after photoexcitation (PL $\left.\right|_{t=0}$ ), rather than the integrated PL intensity. (c) PL decay dynamics of the $\mathrm{Cs}_{2} \mathrm{AgBiBr}_{6}$, $\mathrm{Cs}_{2} \mathrm{AgBiBr}_{6} / \mathrm{PC}_{61} \mathrm{BM}$ and $\mathrm{Cs}_{2} \mathrm{AgBiBr}_{6} /$ Spiro-OMeTAD films. (d) The photocurrent of the $\mathrm{Cs}_{2} \mathrm{AgBiBr}_{6}$ devices as a function of solution concentration. 


\section{Submitted to

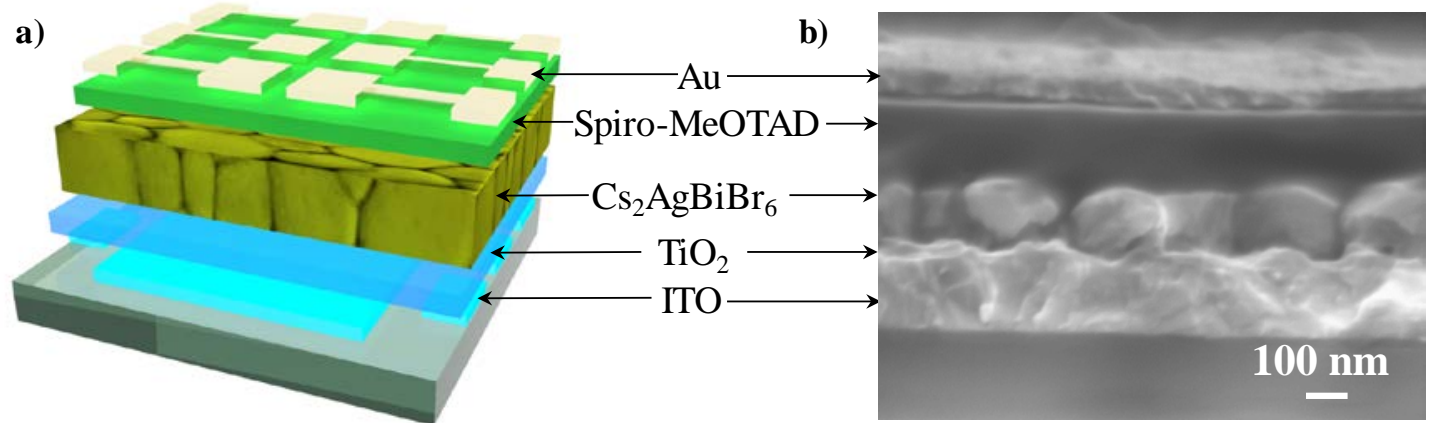

c)

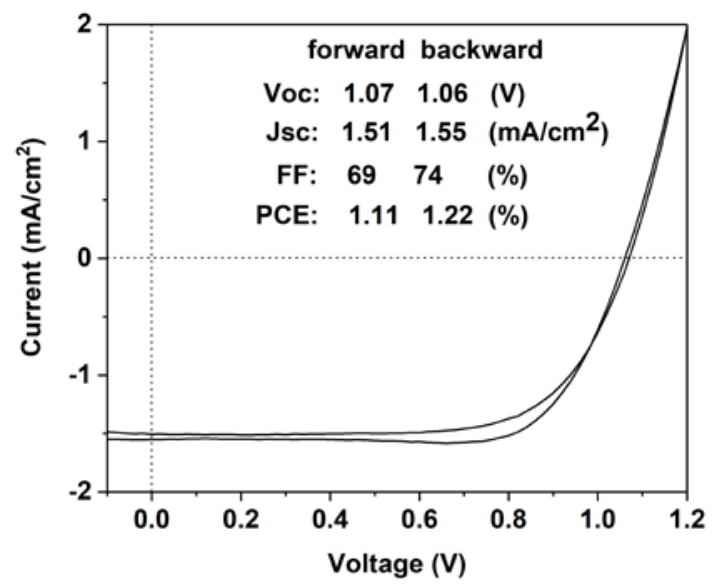

d)

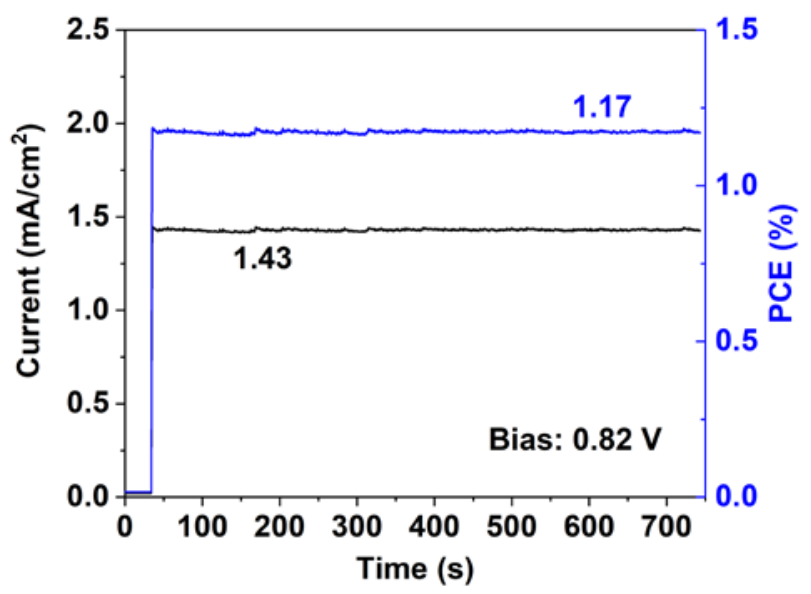

Figure 3. (a) Planar $\mathrm{Cs}_{2} \mathrm{AgBiBr}_{6}$ solar cell structure, ITO/compact $\mathrm{TiO}_{2} / \mathrm{Cs}_{2} \mathrm{AgBiBr}_{6} / \mathrm{Spiro-}$ MeOTAD/Au. (b) Cross-sectional SEM image of $\mathrm{Cs}_{2} \mathrm{AgBiBr}_{6}$ solar cells. (c) $J$ - $V$ curve of the optimized device. (d) The stabilized power output of the $\mathrm{Cs}_{2} \mathrm{AgBiBr}_{6}$ solar cells with a bias of $0.82 \mathrm{~V}$. 


\section{Submitted to

The table of contents entry: We fabricated $\mathrm{Cs}_{2} \mathrm{AgBiBr}_{6}$ films composed of high-crystalquality grains with diameters equal to the film thickness. These high-quality double perovskite films show electron-hole diffusion lengths greater than $100 \mathrm{~nm}$, enabling the fabrication of planar structure double perovskite solar cells with a maximum value of $1.22 \%$.

Keywords: double perovskite, lead free, long diffusion length, planar solar cell

Authors: Weihua Ning, Feng Wang, Bo Wu, Jun Lu, Zhibo Yan, Xianjie Liu, Youtian Tao, Jun-Ming Liu, Wei Huang, Mats Fahlman, Lars Hultman, Tze Chien Sum,* and Feng Gao*

Title: Long Electron-Hole Diffusion Length in High-Quality Lead-Free Double Perovskite Films

ToC figure

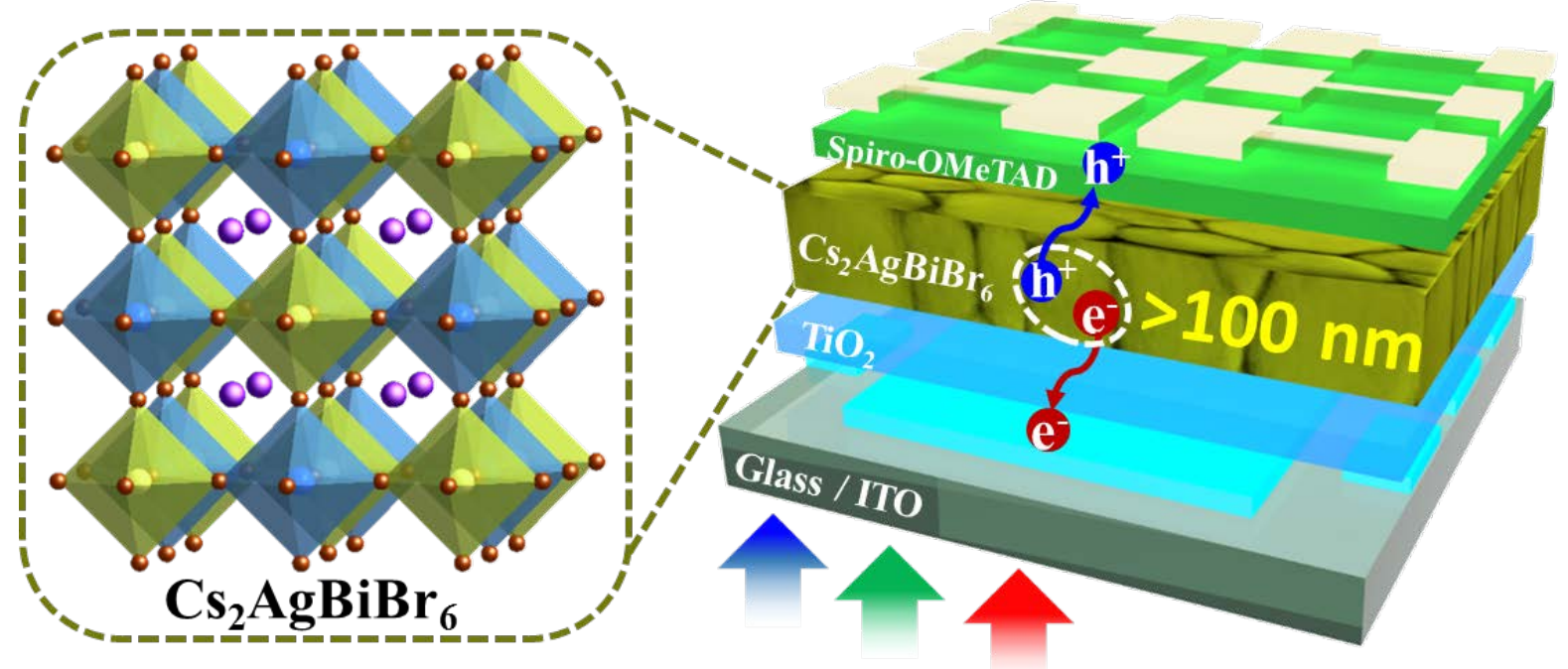


ubmitted to

Copyright WILEY-VCH Verlag GmbH \& Co. KGaA, 69469 Weinheim, Germany, 2017.

\section{Supporting Information}

\section{Long Electron-Hole Diffusion Length in High-Quality Lead-Free Double Perovskite Films}

Weihua Ning, Feng Wang, Bo Wu, Jun Lu, Zhibo Yan, Xianjie Liu, Youtian Tao, Jun-Ming Liu,Wei Huang, Mats Fahlman, Lars Hultman, Tze Chien Sum,* and Feng Gao*

We used the Elliott formula to analyze the UV-Vis absorption profile for thin films that are dominated by direct band edge and direct exciton transitions:

$\alpha(E)=A \cdot \theta\left(E-E_{\mathrm{g}}\right) \cdot\left(\frac{\pi e^{\pi \Delta}}{\sinh (\pi \Delta)}\right)+A \cdot R_{\mathrm{ex}} \cdot \sum_{n_{\mathrm{ex}}=1}^{\infty} \frac{4 \pi}{n_{\mathrm{ex}}^{3}} \delta\left(E-E_{\mathrm{g}}+\frac{R_{\mathrm{ex}}}{n_{\mathrm{ex}}^{2}}\right)$

where $A$ is a constant determined by the transition matrix element, $E_{\mathrm{g}}$ is the bandgap, $\theta$ is the step function, $R_{\mathrm{ex}}$ is the exciton binding energy, $\Delta$ is defined as $\Delta=\sqrt{\frac{R_{\mathrm{ex}}}{E-E_{\mathrm{g}}}}, \delta$ is a delta function and $n_{\mathrm{ex}}$ is the principle quantum number. The step and delta functions were convoluted with a Gaussian broadening. The main fitting results are listed in Table S1 and Figure S2.

Table S1. Fitting parameters used in the Elliott formula. $R_{\mathrm{ex}}$ is the direct exciton binding energies. $\sigma_{\mathrm{c}}$ and $\sigma_{\mathrm{ex}}$ are the Gaussian broadening used in the fitting for the excitonic and continuum bands, respectively.

\begin{tabular}{cccc}
\hline$E_{\mathrm{gd}}(\mathrm{eV})$ & $R_{\mathrm{ex}}(\mathrm{meV})$ & $\sigma_{\mathrm{c}}(\mathrm{meV})$ & $\sigma_{\mathrm{ex}}(\mathrm{meV})$ \\
& & & \\
\hline $3.26 \pm 0.01$ & $440 \pm 10$ & $160 \pm 10$ & $110 \pm 10$ \\
\hline
\end{tabular}

Carrier density dependent PL intensity: The mid-gap trap states assisted recombination could be another reason for the monomolecular recombination and usually results in non-radiative recombination. However, it would not affect the initial PL intensity. Reasons are as follows: 
The PL kinetics can be expressed as:

\section{ADANCEPS
MATERRALIS}

$$
\frac{d n(t)}{d t} \cong-k_{1} n(t)-k_{n r} n(t)-k_{2} n(t)^{2},(1)
$$

where $k_{1}$ is the radiative recombination rate with the doped carrier, $k_{2}$ is the band edge electronhole radiative recombination coefficient and $k_{n r}$ is the non-radiative recombination rate via traps. The PL intensity at any time is:

$$
I(t)=-k_{1} n(t)+k_{2} n(t)^{2},(2)
$$

The carrier density is dependent on $k_{n r}$, which contributes to the lifetime of the PL. However, since the initial carrier density is fixed (by photoexcitation density) when $t$ approaches zero, the initial PL intensity can be expressed as:

$$
I_{0}=-k_{1} n_{0}+k_{2} n_{0}^{2},(3)
$$

which does not rely on the non-radiative recombination rate. This is why we choose PL intensity ( $t \sim 0)$ to investigate the origin of the PL from doped carriers, excitons or band edge. 


\section{ADVANCED}

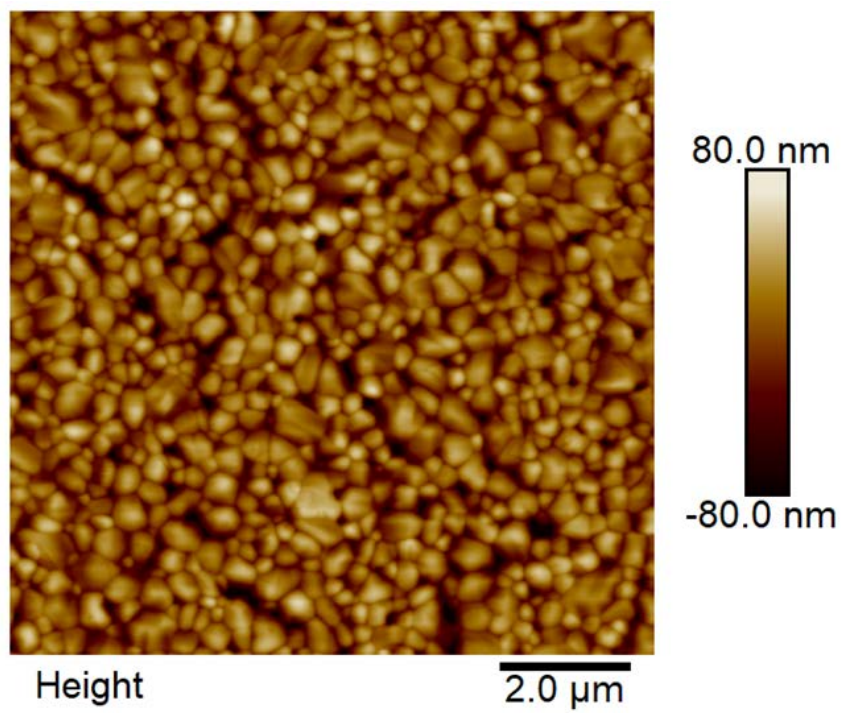

Figure S1. Typical AFM image from a $\mathrm{Cs}_{2} \mathrm{AgBiBr}_{6}$ film. 


\section{Submitted to

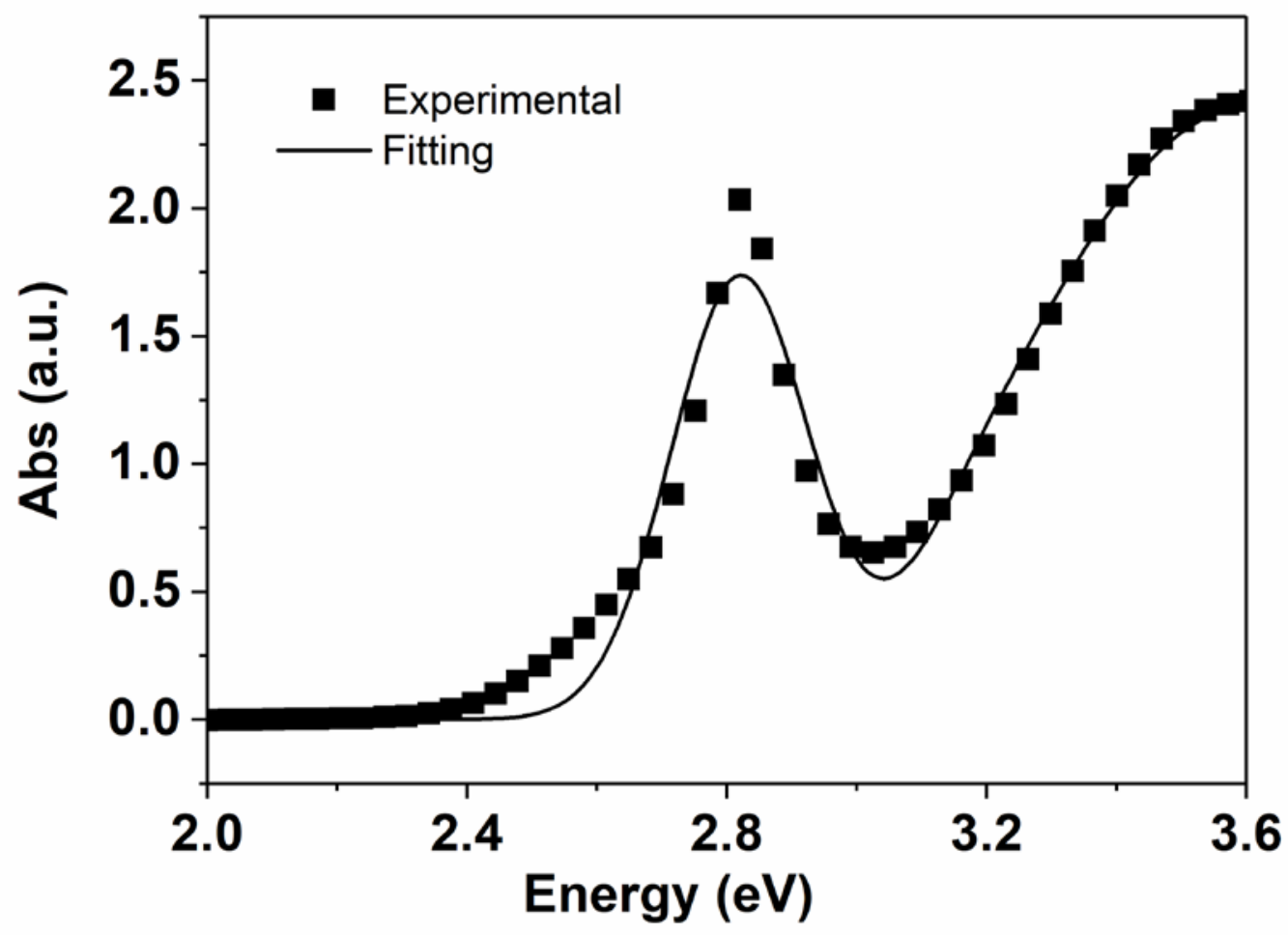

Figure S2. The UV-Vis absorption of the $\mathrm{Cs}_{2} \mathrm{AgBiBr}_{6}$ film fitted using the Elliott formula. 


\section{ADVANCED \\ Submitted to

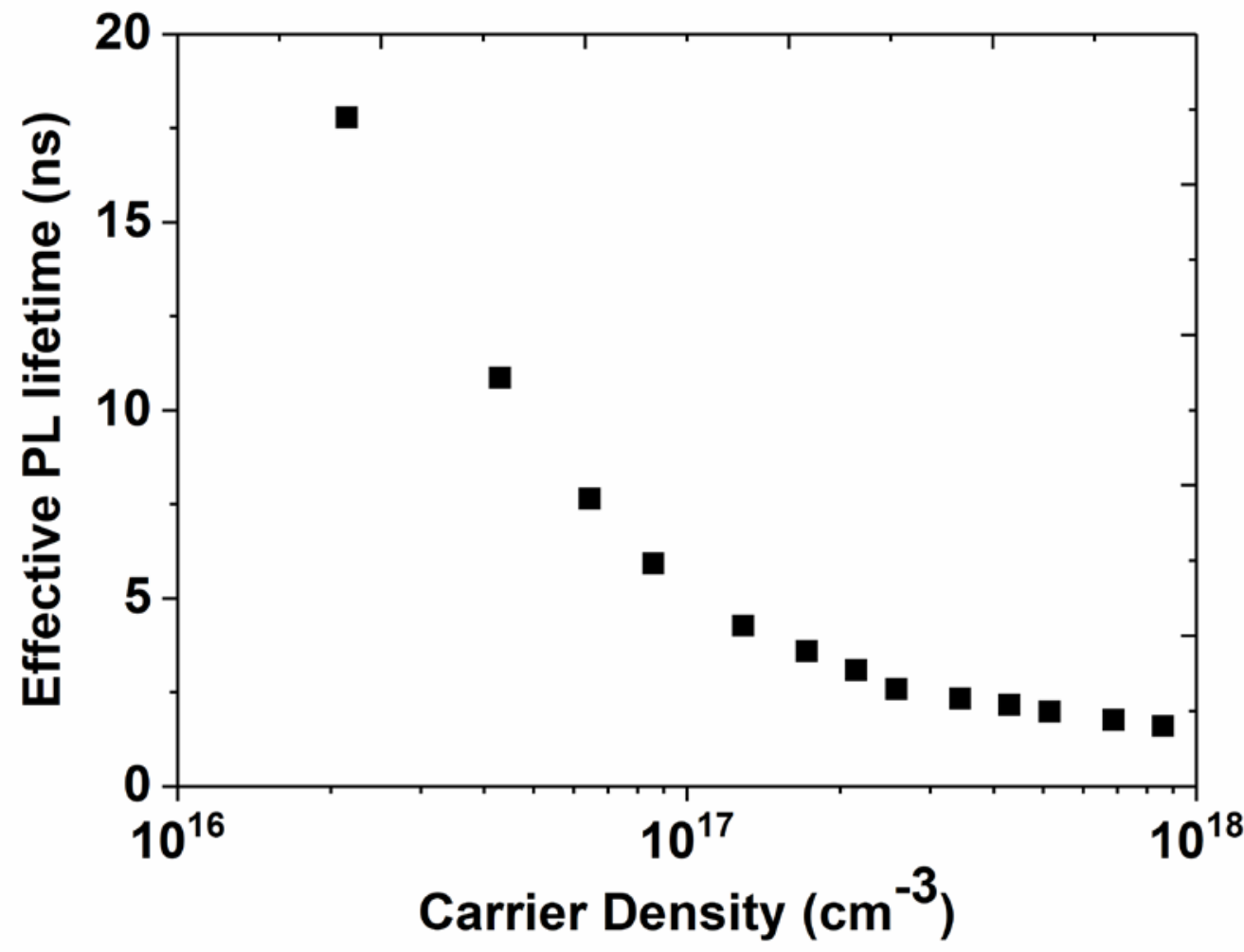

Figure S3. The effective PL lifetime of the $\mathrm{Cs}_{2} \mathrm{AgBiBr}_{6}$ film as a function of carrier density. 


\section{ADANCEPS
MATERRALIS}

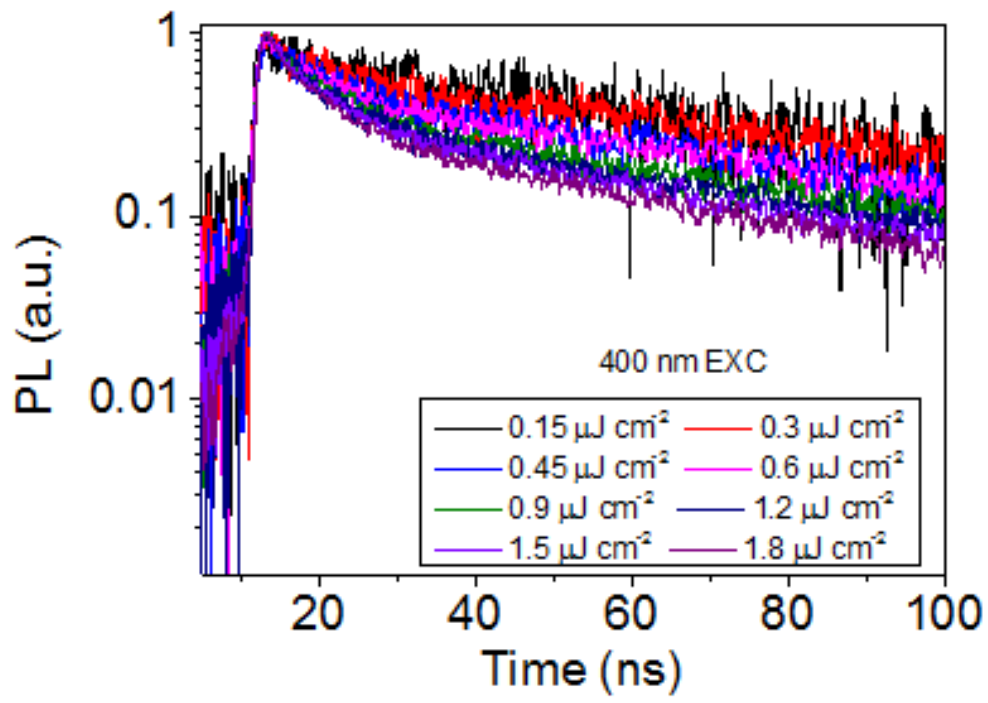

Figure S4. Normalized PL kinetics under different excitation fluence (400 nm). 

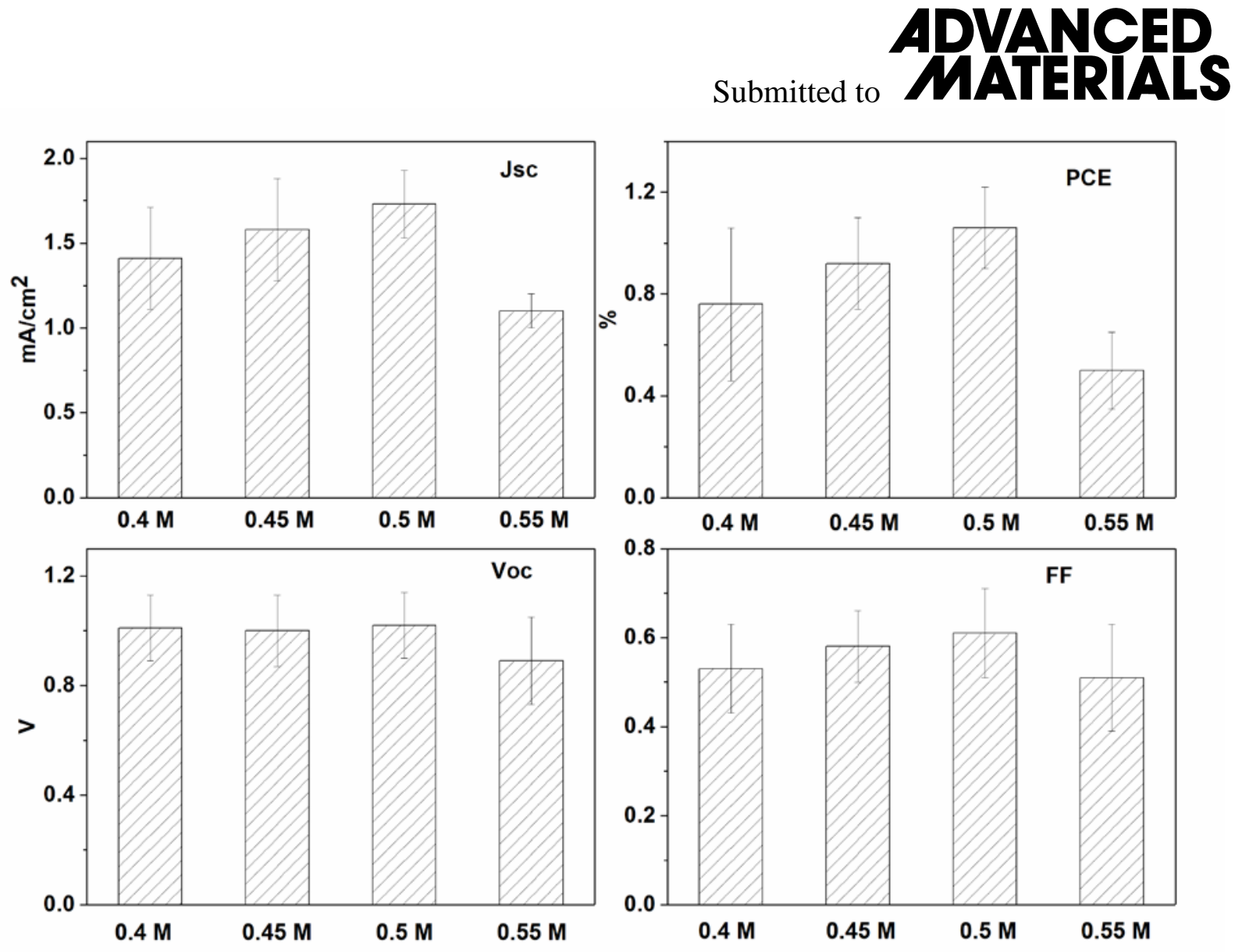

Figure S5. Device performance as a function of solution temperature. Data were averaged from 20 devices per solution. The $\mathrm{Cs}_{2} \mathrm{AgBiBr}_{6}$ films were annealed at $250{ }^{\circ} \mathrm{C}$ for $5 \mathrm{~min}$. 


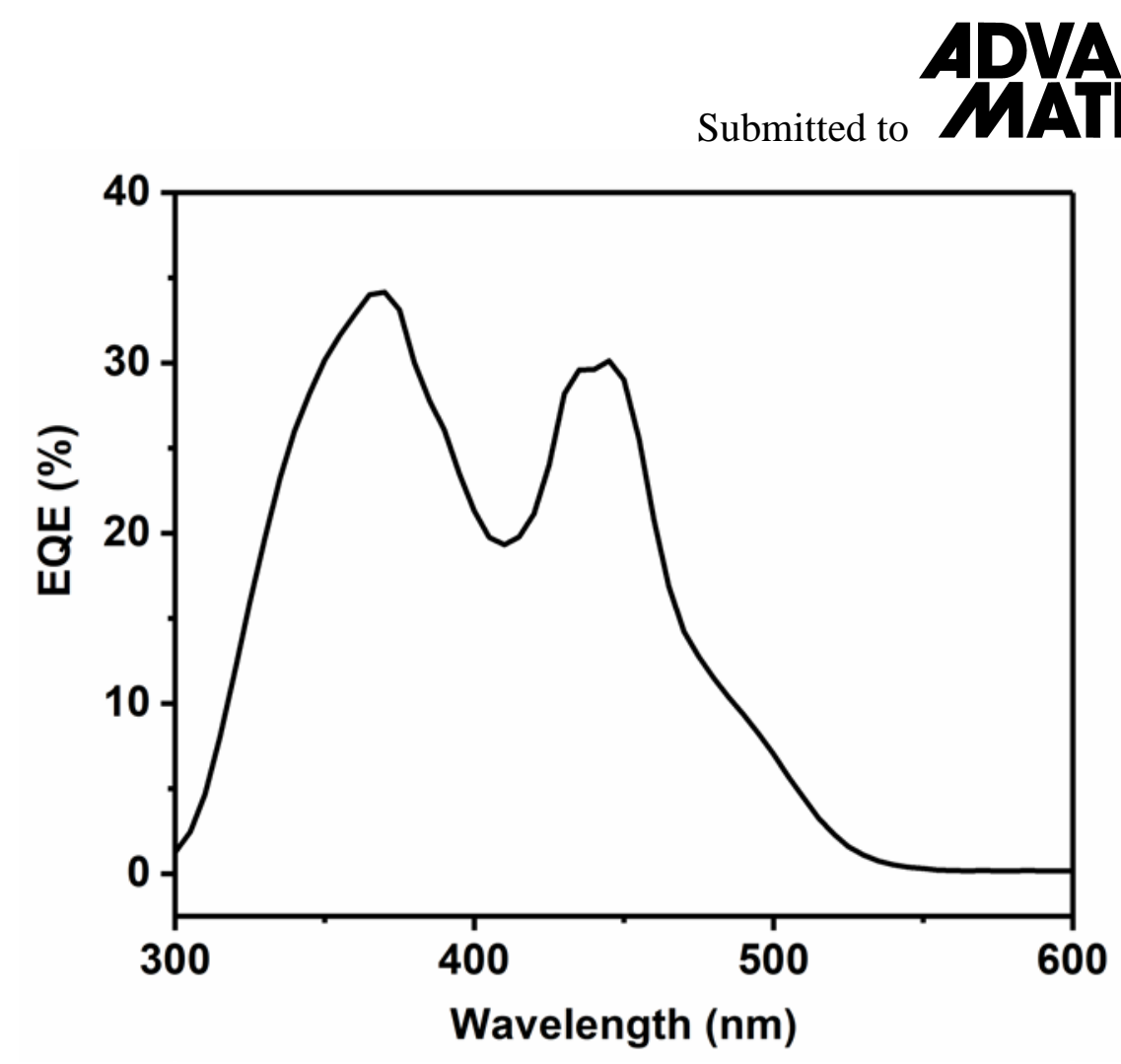

Figure S6. External quantum efficiency (EQE) spectra of a $\mathrm{Cs}_{2} \mathrm{AgBiBr}_{6}$ solar cell. 

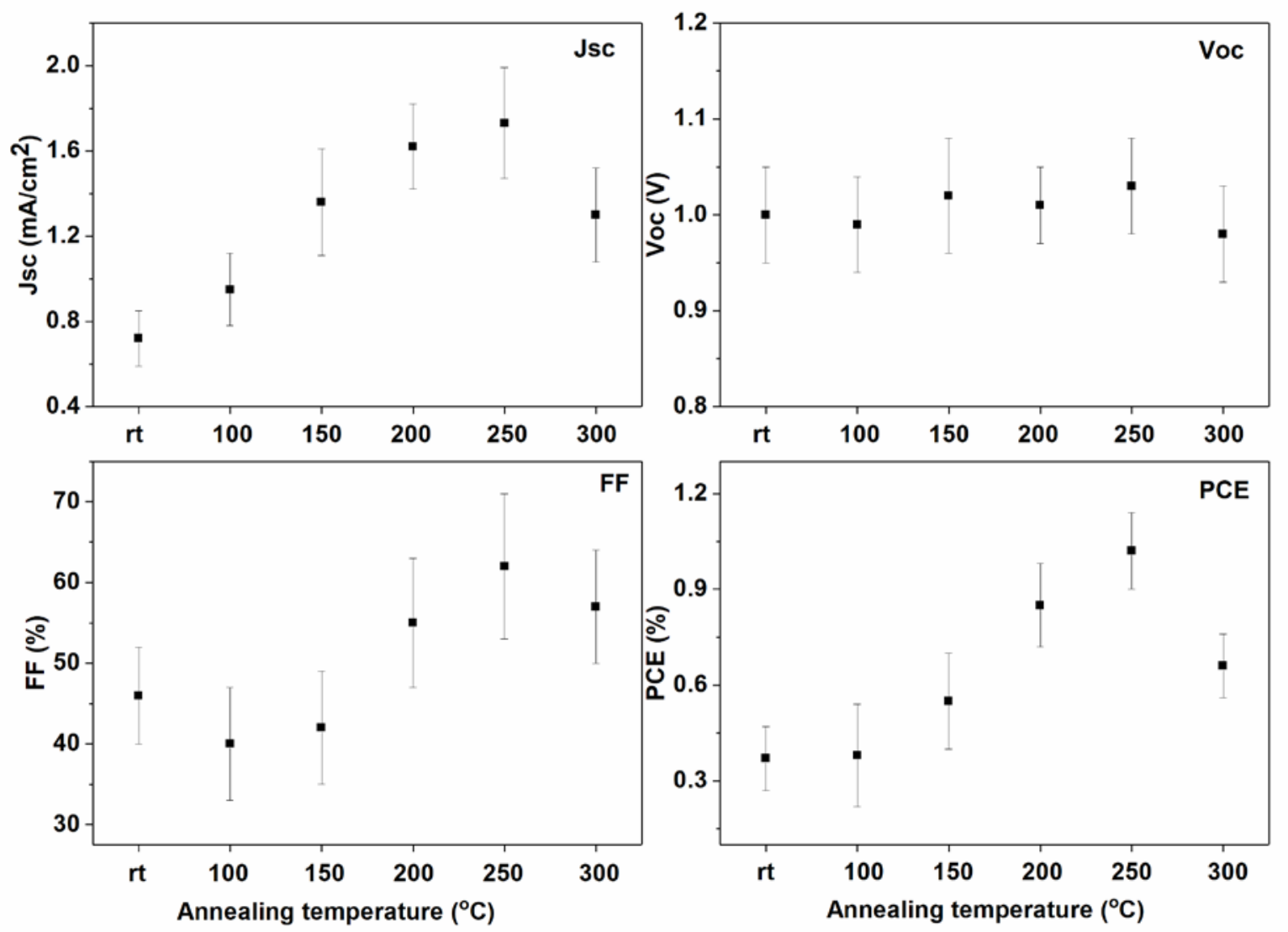

Figure S7. Device performance as a function of annealing temperature. Data are averaged from 20 devices per annealing temperature. The concentration of the $\mathrm{Cs}_{2} \mathrm{AgBiBr}_{6}$ solution is $0.55 \mathrm{M}$. 


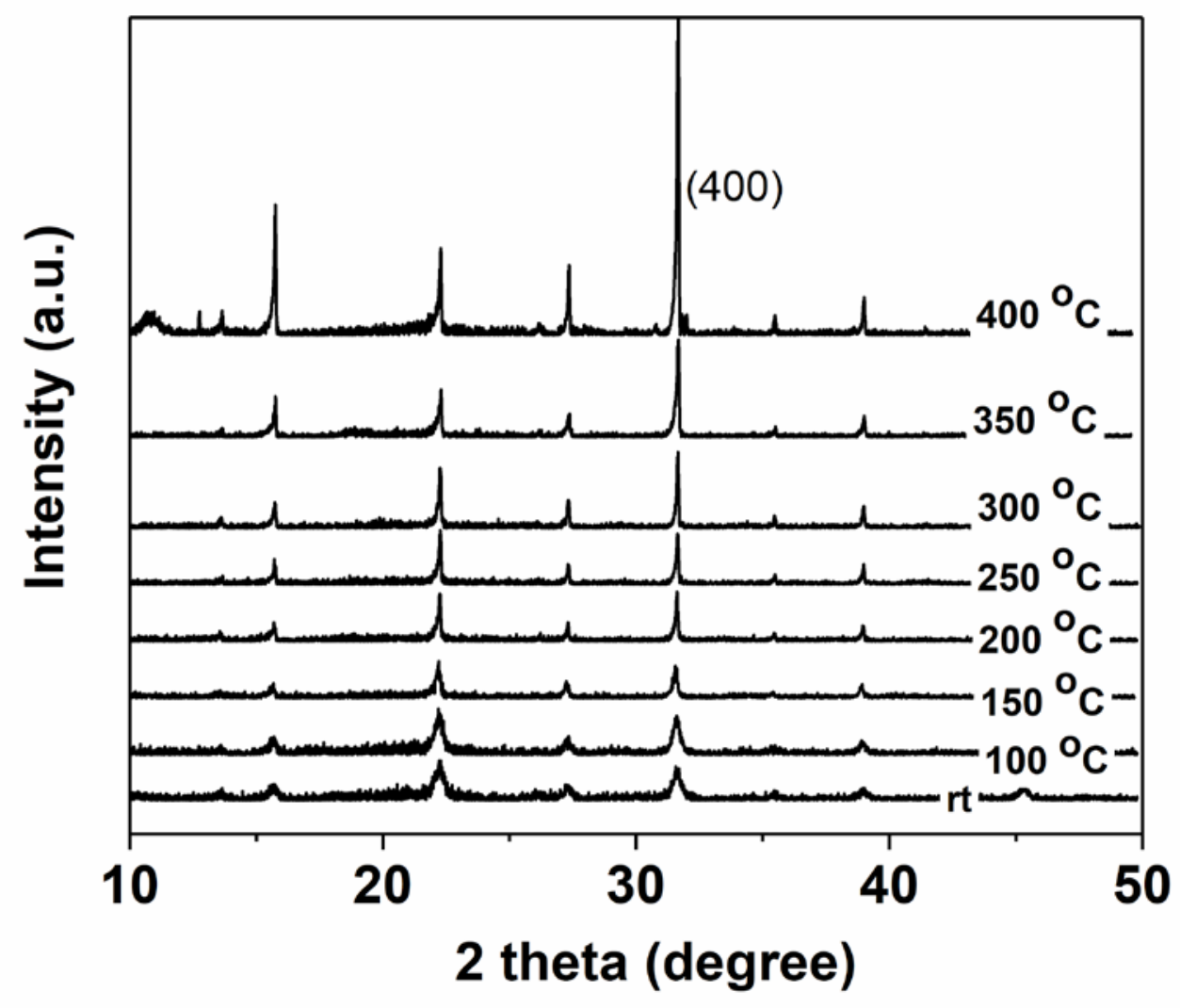

Figure S8. XRD patterns of the $\mathrm{Cs}_{2} \mathrm{AgBiBr}_{6}$ films with different annealing temperatures. 


\section{ADVANCEP \\ Submitied to MATERIALS}
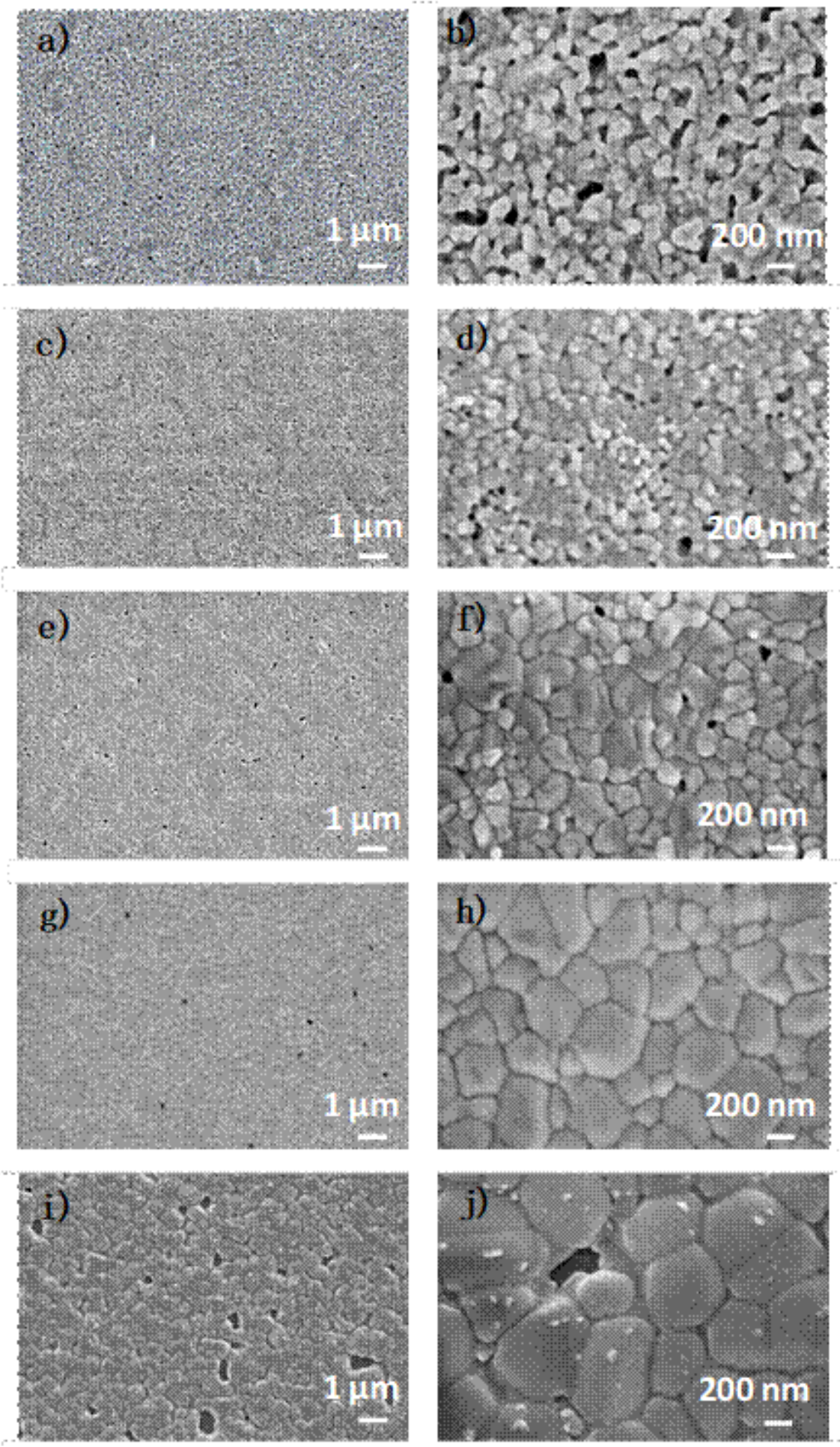

Figure S9. SEM images of $\mathrm{Cs}_{2} \mathrm{AgBiBr}_{6}$ films with different annealing temperatures. (a, b)

Room temperature, (c, d) $100{ }^{\circ} \mathrm{C}$, (e, f) $200^{\circ} \mathrm{C}$, (g, h) $250^{\circ} \mathrm{C}$, and (i, j) $300^{\circ} \mathrm{C}$. 


\section{ADVANCED \\ Submitted to \\ MATERIALS}

a)

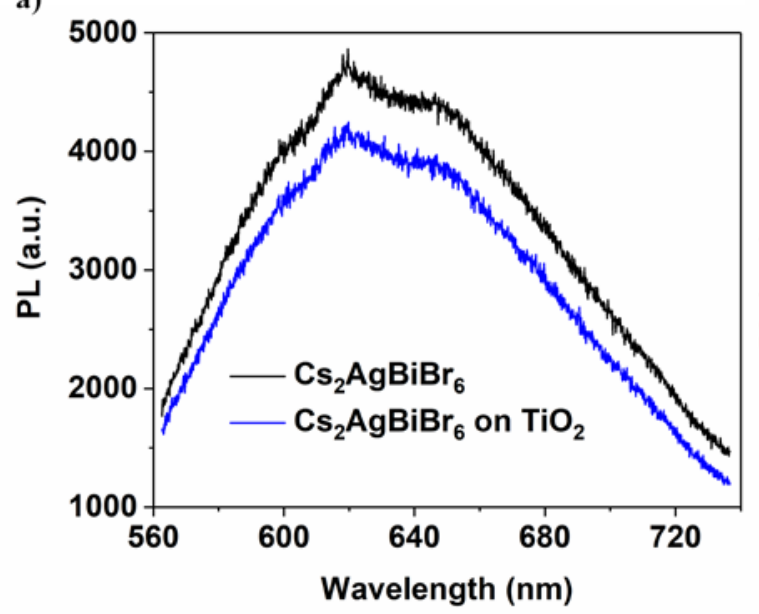

b)

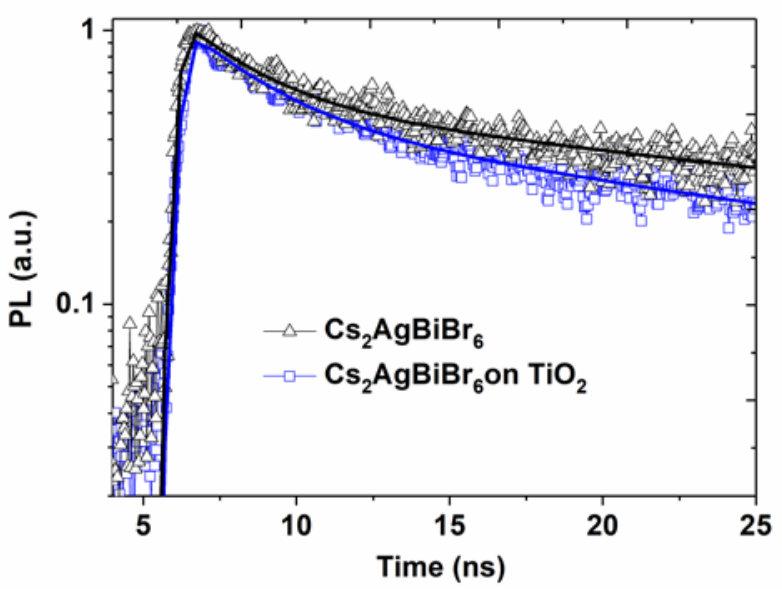

Figure S10. (a) PL and (b) PL decay dynamics of the $\mathrm{Cs}_{2} \mathrm{AgBiBr}_{6}$ and $\mathrm{Cs}_{2} \mathrm{AgBiBr}_{6} / \mathrm{TiO}_{2}$ films. 
ADVANCED

a)

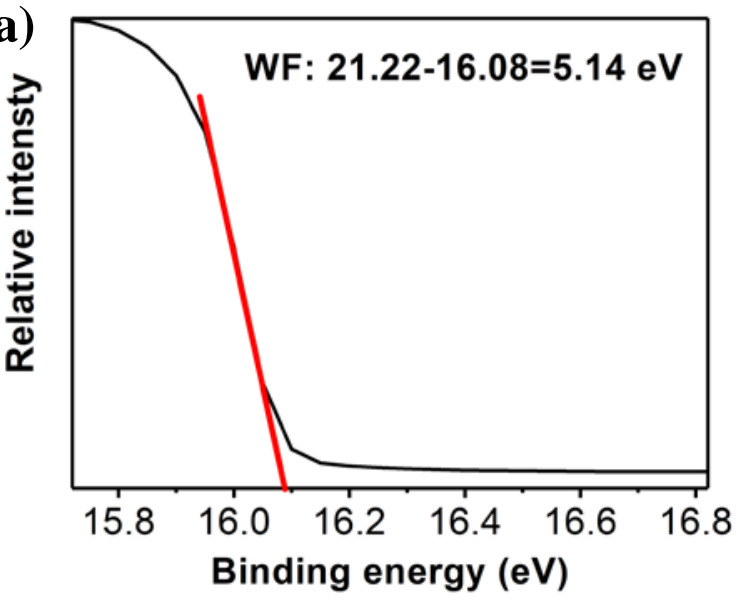

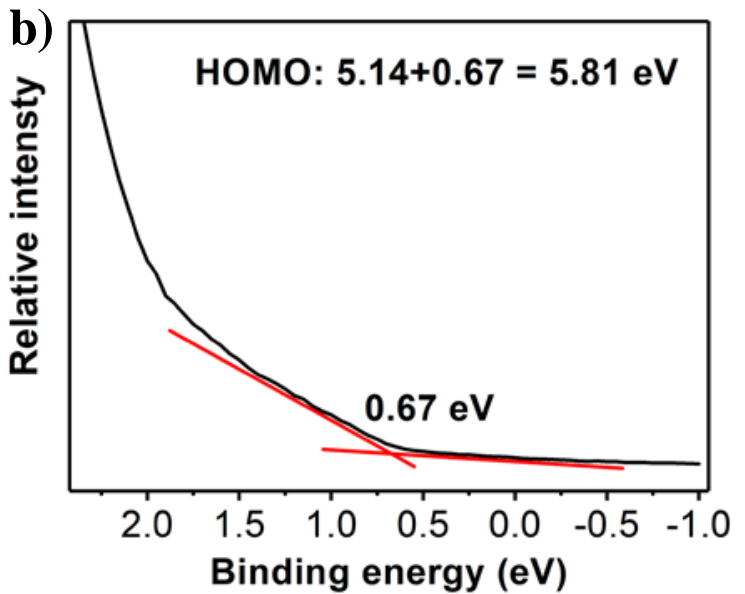

Binding energy $(\mathrm{eV})$

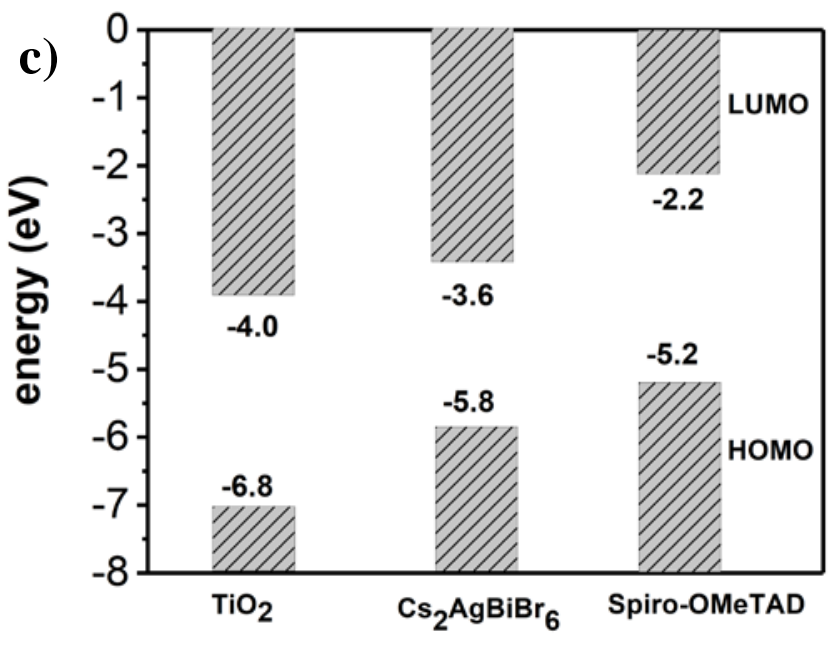

Figure S11. (a, b) UPS spectra of $\mathrm{Cs}_{2} \mathrm{AgBiBr}_{6}$ films. (c) Energy level diagram of double perovskite solar cells. 


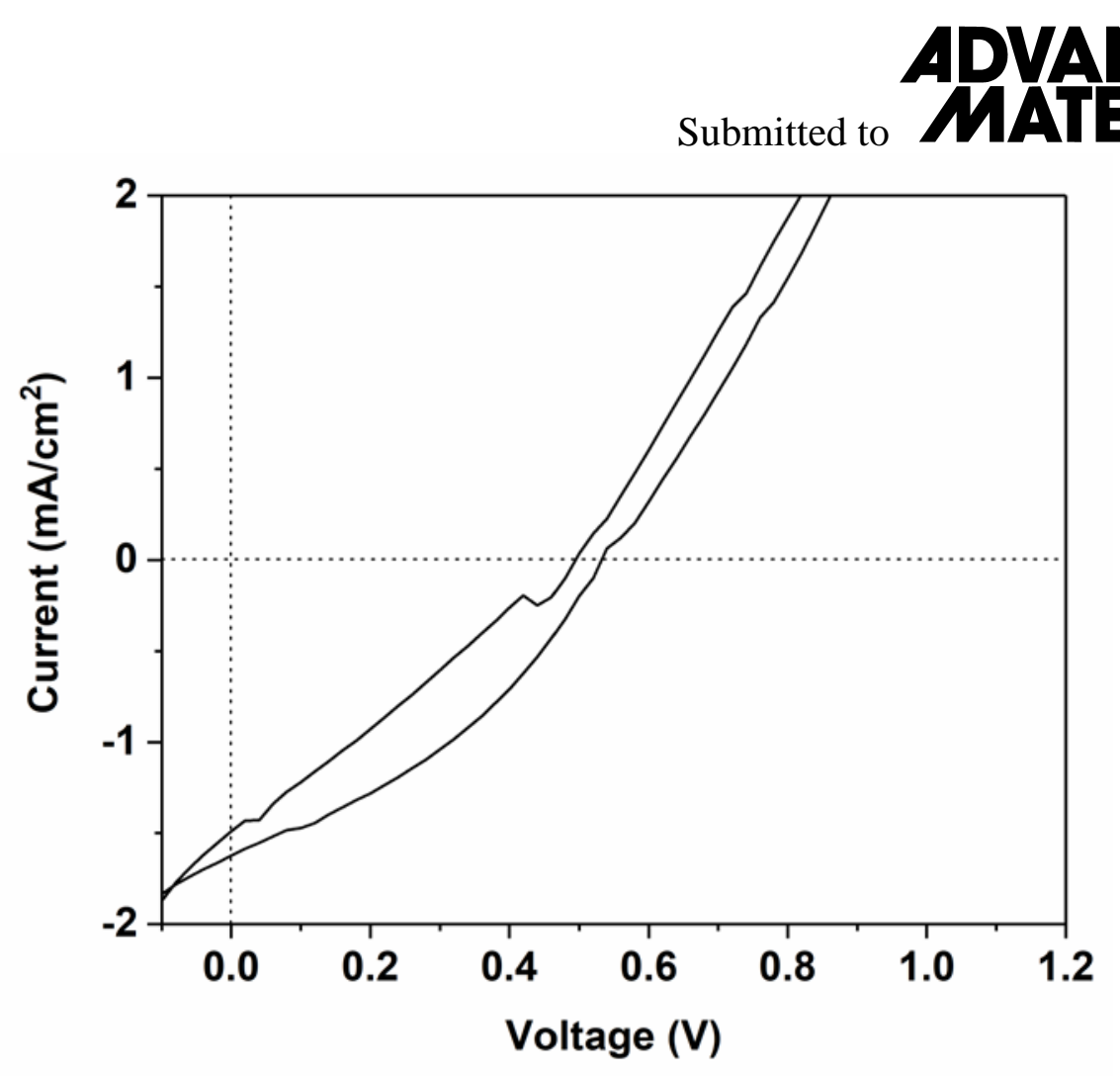

Figure S12. J-V curve of a $\mathrm{Cs}_{2} \mathrm{AgBiBr}_{6}$ solar cell device without $\mathrm{TiO}_{2}$ as the ETL. Device structure: ITO/Cs $2 \mathrm{AgBiBr}_{6} / \mathrm{Spiro}-\mathrm{MeOTAD} / \mathrm{Au}$. 


\section{ADNANED
MATERRALS}

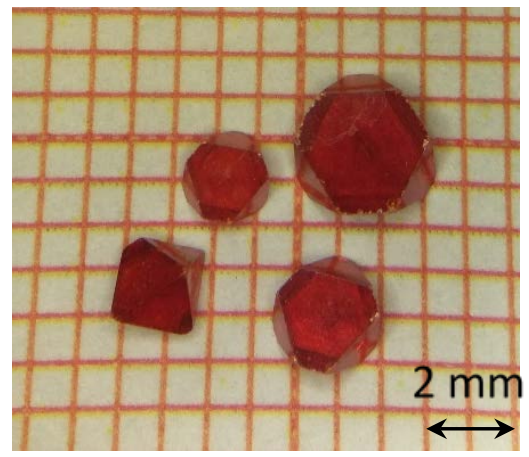

Figure S13. Photographs taken from the as-grown $\mathrm{Cs}_{2} \mathrm{AgBiBr}_{6}$ crystals. 